\title{
Review \\ Value of anti-infective chemoprophylaxis in primary systemic vasculitis: what is the evidence?
}

\author{
Frank Moosig, Julia U Holle and Wolfgang L Gross
}

Department of Rheumatology, University Hospital of Schleswig Holstein and Klinikum Bad Bramstedt, Oskar Alexander Str. 26, 24576 Bad Bramstedt, Germany

Corresponding author: Frank Moosig, moosig@klinikumbb.de

Published: 28 October 2009

This article is online at http://arthritis-research.com/content/11/5/253

(c) 2009 BioMed Central Ltd
Arthritis Research \& Therapy 2009, 11:253 (doi:10.1186/ar2826)

patient number and availability of at least some data on infectious complications (Table 1). Regarding AIP, these data still have to be interpreted with caution: infection rates are documented and published with varying degrees of accuracy depending on the design of the studies. Mild and moderate infections - that is, those not requiring hospitalisation - appear to be underestimated, whereas it can be assumed that deaths due to infections are reported thoroughly.

Furthermore, there are great variations in the use of AIP: some trials used routine prophylaxis against Pneumocystis jiroveci pneumonia (PCP; formerly named Pneumocystis carinii), other fungi and cytomegalovirus (CMV), and others did not. Most protocols left the use of AIP optional and in many the actual use was not even recorded, or at least not reported. Finally, the therapeutic intervention is given infrequently in sufficient detail; for example, the cumulative dose of glucocorticoids (GCs) is usually not mentioned.

When thinking about AIP, both the individual risk for the patient and the evidence for the efficiency and safety of the prophylactic intervention must be taken into account.

\section{Factors influencing susceptibility to infections}

Because, to date, no PSV trials have used infection as the primary endpoint, information on possible risk factors can only be retrieved from adverse event reporting in cohort studies or therapeutic trials. In Table 1 the rates of infections, serious infections and fatal infections in different entities and under distinct medication are summarised. In conjunction with data from other medical conditions the following conclusions might be drawn.

Hever, some conclusions might be drawn from therapeutic trials and cohort studies. For this purpose we analysed 35 such trials [4-37], which were selected according to quality,

$\mathrm{AAV}=\mathrm{ANCA}$ associated vasculitis; AIP $=$ anti-infective prophylaxis; ANCA $=$ antineutrophil cytoplasmic antibody; BSR $=$ British Society for Rheumatology; CMV = cytomegalovirus; Cyc = cyclophosphamide; EULAR = European League Against Rheumatism; GC = glucocorticoid; GCA = giant cell arteritis; $\mathrm{HZ}=$ herpes zoster; $\mathrm{MTX}=$ methotrexate; $\mathrm{PCP}=$ Pneumocystis jiroveci pneumonia; $\mathrm{PSV}=$ primary systemic vasculitis; $\mathrm{SVV}=$ small vessel vasculitis; TB $=$ tuberculosis; $\mathrm{TNF}=$ tumour necrosis factor; $\mathrm{T} / \mathrm{S}=$ trimethoprim/sulfamethoxazole; $\mathrm{VZV}=$ varicella-zoster virus; $\mathrm{WG}=$ Wegener's granulomatosis. 


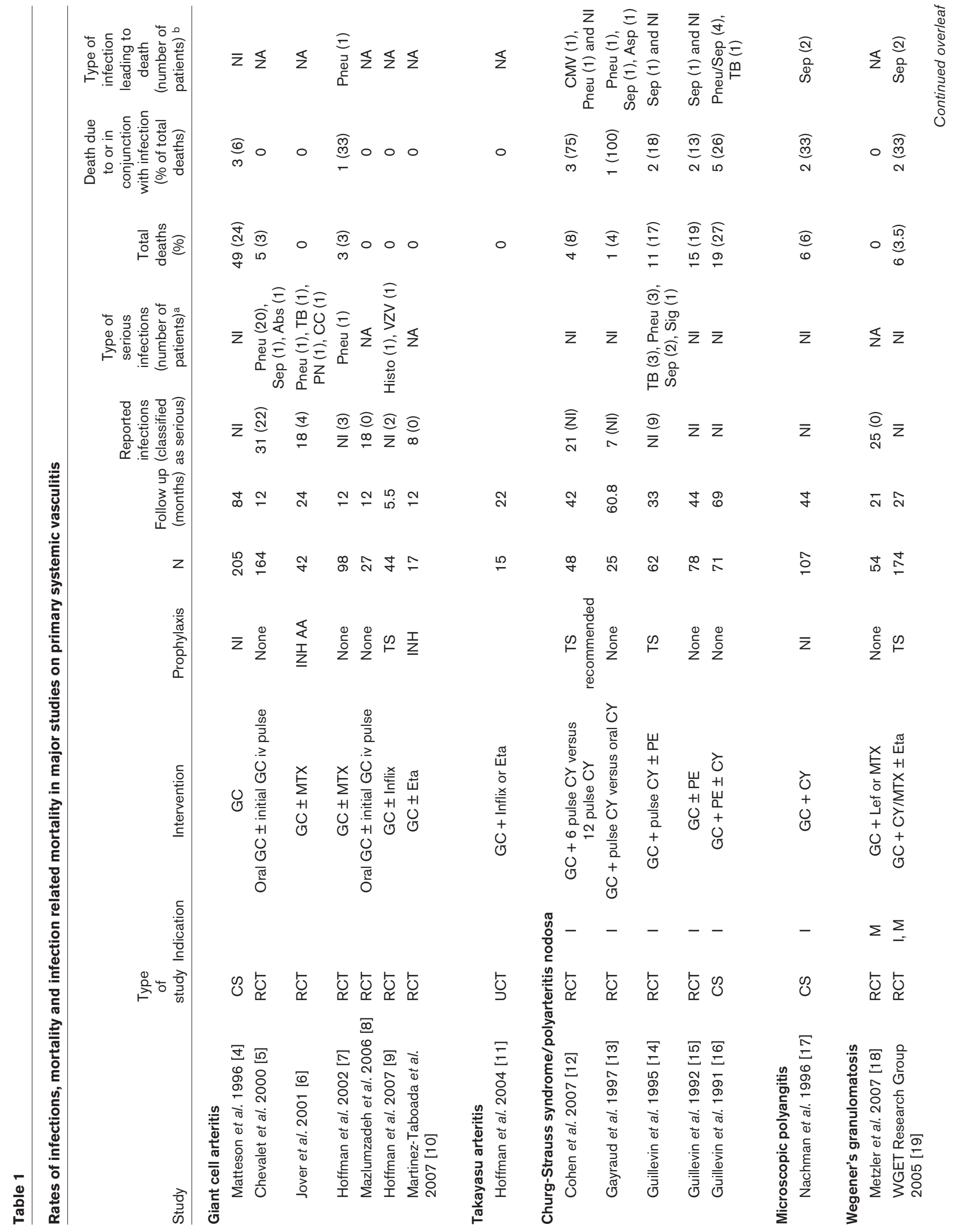




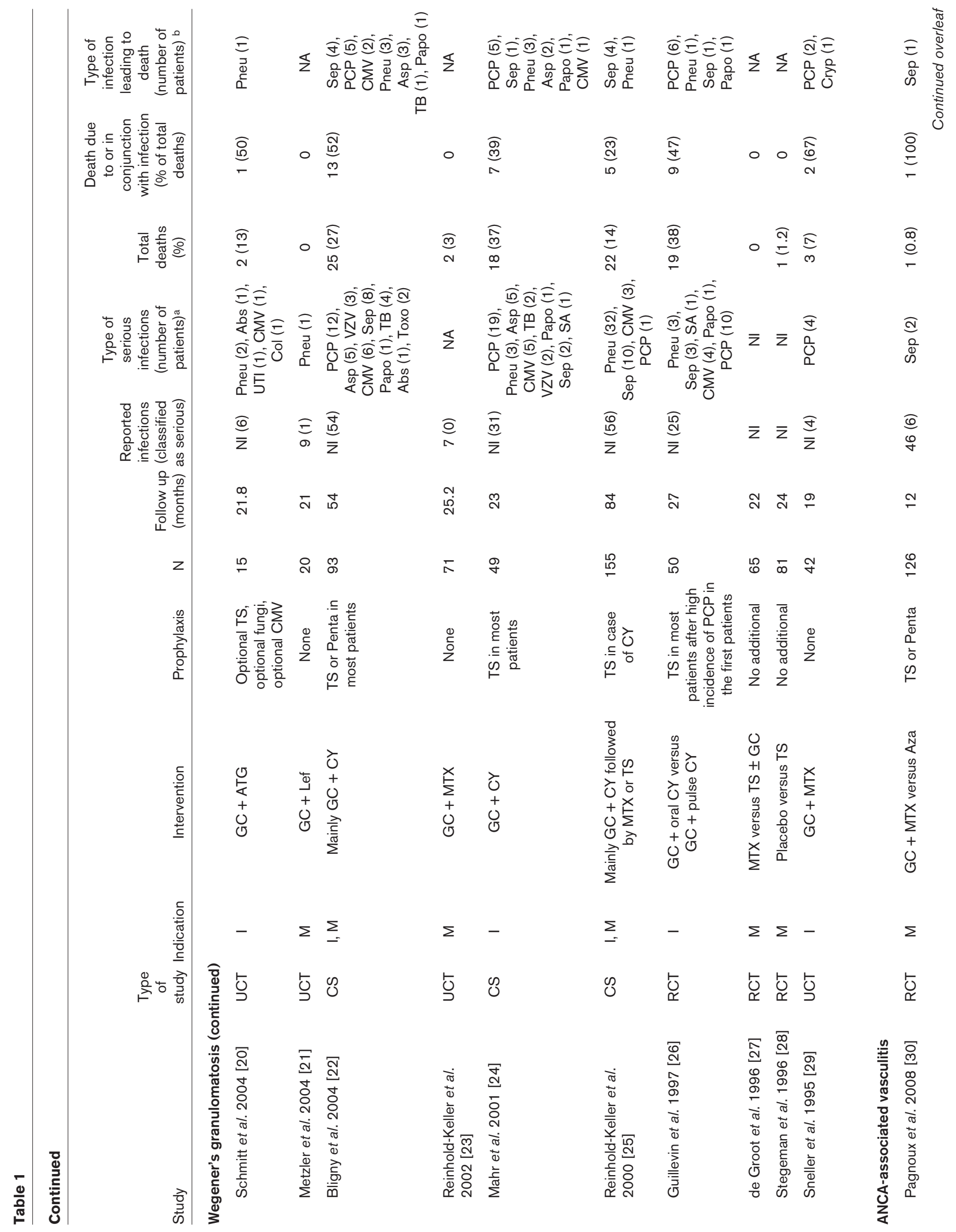




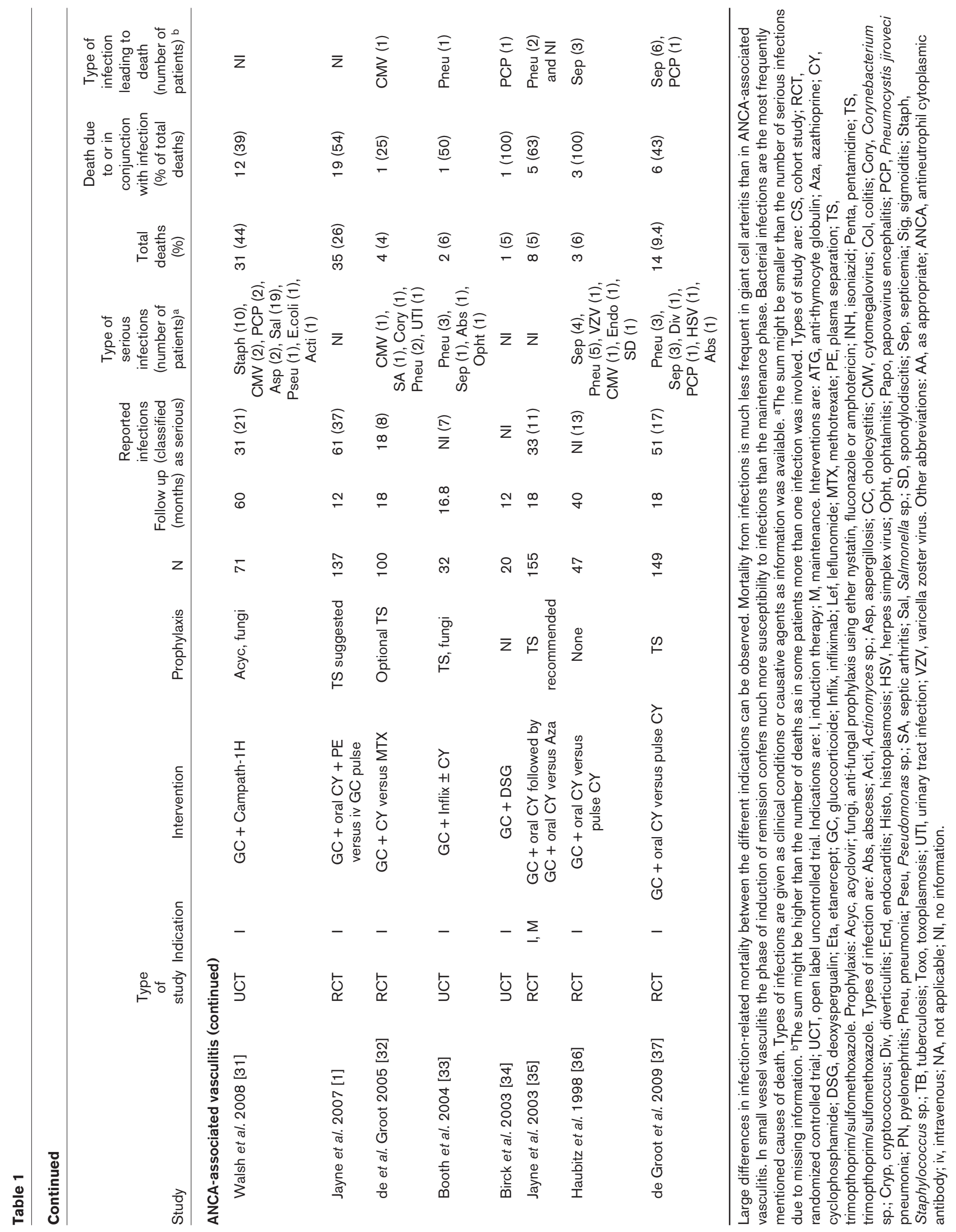




\section{Medication}

It is obvious that immunosuppressive medication is a major risk factor for infections [38]. A high GC dose (often defined as more than $30 \mathrm{mg}$ per day prednisolone-equivalent), especially in the form of intravenous methylprednisolone, is a significant risk factor $[1,39]$. With respect to common clinical experience, its importance seems to be underestimated in clinical trials because, for example, the cumulative GC dose is not usually stated. In a study on giant cell arteritis (GCA) solely treated with GCs, $86 \%$ of the patients experienced severe GC-related adverse events, including severe infections in 31\% [40]. Schmidt and colleagues [41] reported a relative risk of severe infections - that is, infections leading to hospitalisation - of 2.44 in the first 6 months of GC treatment in a large GCA trial and increased infection-related mortality. Rising awareness of GC complications, including infections, makes GC sparing an increasingly important aim. According to the European League Against Rheumatism (EULAR) recommendations for conducting clinical trials in PSV, protocols should be designed to reduce patients' total exposure to GCs, which includes recording cumulative GC doses and the use of GC-sparing drugs like methotrexate (MTX) [42].

Although some trials using cyclophosphamide (Cyc) report very low rates of infectious complications [17,33], Cyc use in SVV is associated with higher rates of infections and fatalities than the use of medium potent immunosuppressants such as MTX, azathioprine or leflunomide [22,24,26]. Among the latter no differences concerning rates and types of infections can be derived from the available data. When analysing infectious complications, it has to been taken into account that treatment changes over time. For example, the CYCAZAREMtrial demonstrated that oral Cyc could safely be substituted by azathioprine after achieving remission, leading to much lower cumulative Cyc doses [35]. The use of Campath-1 $\mathrm{H}$, a monoclonal antibody to CD52 that leads to lymphocyte depletion and profound neutropenia, was associated with high rates of infectious complications, as was expected from experience with its use in haematology [32]. A clear association of drugs with specific types of infections, as is known for tuberculosis (TB) and anti-TNF- $\alpha$ agents, can not be derived from the still limited data from PSV trials.

\section{Types of vasculitis}

As shown in Table 1, there are large differences regarding the forms of PSV and their infection-related mortality. Infections and mortality from infectious complications are much more prevalent in SVV than in large vessel vasculitis. In GCA trials, mortality ranged from 0 to 0.03 deaths per patient year and infections caused 0 to $33 \%$ of these deaths [4-11]. In SVV this range was 0 to 0.26 deaths per patient year and infections were involved in 0 to $100 \%$ of the fatal events [1,17-37].

Interestingly, in most published clinical trials in GCA, PCP prophylaxis was not used. Despite the fact that high doses of
GCs are a major risk factor for the development of PCP, no case of PCP has been reported within these trials [4-10]. In contrast, patients with antineutrophil cytoplasmic antibodies (ANCA)-associated vasculitis (AAV), especially those with Wegener's granulomatosis (WG), are at high risk for PCP that can not be attributed only to medication [18-29]. There is evidence that at least some entities within the group of PSV confer an altered function of the immune defence per se. In $W G$, for instance, the granulomatous inflammation of the upper respiratory tract leads to destruction of the barrier function of the surfaces, possibly allowing for invasion of pathogens [43]. It may also be possible that a primary barrier deficiency not only promotes infections but has a role in the aetiology of the disease itself [44].

\section{Disease stage and phase of therapy}

In PSV, and especially in SVV, the therapeutic approach usually consists of an induction of remission and a maintenance phase (for review, see [45]). For induction, more aggressive regimens, including Cyc and higher GC doses, are utilised. Furthermore, in SVV the selection of drugs depends on the stage of the disease: in the localised and early systemic stage - that is, disease without threatened vital organ function - induction of remission is usually attempted with medium potent immunosuppressants such as MTX, whereas in generalised and severe disease - that is, with threatened vital organ function or organ failure, respectively Cyc is used.

In SVV the induction of the remission period is the most vulnerable phase concerning infections and mortality. From studies assessing only maintenance of remission, published mortality rates ranged from 0 to 0.01 deaths per patient year and infections did not significantly contribute to those fatalities $[18,21,23,27,28,30]$. In contrast, trials on induction of remission in SVV reported mortality rates up to 0.26 per patient year. In those trials infections were responsible for the fatal events in up to $100 \%$, and about $50 \%$ of deaths, on average, were due to infections $[1,17,20,22,24,26,29$, 31-37]. Accordingly, mortality was higher in study populations with more severe disease. The highest reported rate was in SVV patients who presented initially with organ (renal) failure [1]. But even in this population, in which one might expect a higher contribution of uncontrolled disease to the death rate, infections are involved in more than $50 \%$ of the fatal outcomes.

\section{Types of infection and options for prophylaxis Bacterial infections}

In PSV trials Staphylococcus aureus is the isolate for which fatal outcome has been reported most frequently. As demonstrated in surgical patients and patients on dialysis, prophylactic topical treatment with mupirocin ointment for nasal carriers of $S$. aureus leads to a significant reduction in the rate of infections with this agent (relative risk 0.55 according to [46]). Especially in WG, the incidence of nasal 
colonisation with $S$. aureus is higher than in controls and chronic carriage is associated with higher relapse rates [47]. In addition, relapses are often anteceded by infection, mainly of the upper respiratory tract $[48,49]$. Furthermore, it is well documented that trimethoprim/sulfamethoxazole (T/S) treatment reduces the rate of relapse and is able to induce remission in some WG patients, especially those with localised disease $[28,50]$. It is not clear whether this effect is achieved by its antibiotic or its immunomodulatory properties. Although its primary end point was relapse rates, the study by Stegeman and colleagues [28] clearly demonstrated a reduction in respiratory-tract as well as non-respiratory-tract infections using T/S in WG patients in remission. This study can be regarded as the only large scale trial of anti-infective prophylaxis in vasculitis.

As topical mupirocin does not cause serious adverse events [46], it is used in some vasculitis centres during the high risk phase of induction of remission in SVV (seven subsequent days three times daily per month). One concern, however, is that with mupirocin there is an increase in infections other than those due to $S$. aureus [46]. For reasons of possible development of resistance as well as compliance problems, long-term use should be avoided.

Besides topical treatment, systemic antibiotics are another option for AIP, although they have not been used in PSV remission induction trials so far. From randomised controlled trials using, for example, levofloxacine in patients with malignancies during chemotherapy-induced neutropenia $1<500$ neutrophils per microlitre), it is known that a reduction in the incidence of neutropenic fever and hospitalisation can be achieved [2,3]. An effect on mortality has not been demonstrated and there are concerns regarding the longterm outcome of such interventions on microbial resistance in the community. As the treatment of PSV using standard protocols does not usually lead to prolonged neutropenia and the effectiveness of chemoprophylaxis with, for example, levofloxacine with regard to mortality has not been proven in patients treated with more intense chemotherapy, there is no standard setting for which the use of systemic antibacterial prophylaxis can be recommended. Although clear evidence for its use during induction of remission - apart from PCPprophylaxis - is missing, T/S has proven its ability to reduce bacterial infections in patients with WG [28] and, therefore, might be considered in high-risk patients.

Other antibiotics, such as levofloxacine, might only be considered in refractory heavily pre-treated PSV patients undergoing salvage therapy with drugs known to induce severe neutropenia - for example, campath-1 $\mathrm{H}$.

\section{Pneumocystis jiroveci}

The risk of PCP is especially high in patients with SVV undergoing induction therapy. Without using prophylaxis the incidence of PCP is up to $20 \%$ [26] and many fatalities have been reported in earlier trials $[22,24,26,29]$. It has to be mentioned, however, that the causes of deaths in those patients were multi-factorial and often due to several infectious agents simultaneously. Furthermore, some of the mentioned studies referred to the same patient population $[22,24,26]$. In a retrospective analysis, Ognibene and colleagues [51] found an estimated PCP incidence of $6 \%$ in a cohort of 180 WG patients. PCP occurred during induction of remission. Estimating the risk of PCP during induction of remission is further complicated as therapeutic strategies have changed over time, leading to lower cumulative Cyc doses and less frequent use of high dose intravenous GCs. Simultaneously, T/S use as PCP prophylaxis has gained widespread acceptance. Unlike in HIV infection, where a low CD4 count is the strongest risk factor, such factors are insufficiently defined in PSV patients. There is evidence that older age is an independent risk factor [52]. Patients with WG seem to be at increased risk compared to other AAV or PSV patients in general. In WG a low lymphocyte count before and during therapy is associated with PCP [51,52]. Generally speaking, prolonged ( $>1$ month) GC use at doses $>15$ to $20 \mathrm{mg}$ per day is the best defined risk factor [53,54]. Other immunosuppressants, especially Cyc, also increase the risk of PCP [54].

Although, as for all other potential indications for AIP, there are no clinical trial data on PCP prophylaxis in PSV patients, there is some evidence for its use in SVV (level B to C): infection rates were much higher in trials not using prophylaxis than in those recommending it $[22,26]$. Mahr and colleagues [24] introduced T/S prophylaxis during an ongoing protocol as a reaction to high rates of PCP and reported effectiveness. In their analysis, Chung and colleagues [55] concluded that PCP prophylaxis is cost-effective in WG patients unless the annual incidence of PCP fell below $0.2 \%$. According to the EULAR recommendations, T/S prophylaxis is encouraged in all patients being treated with Cyc [56]. The British Society for Rheumatology (BSR) formally recommends PCP prophylaxis at a dose of $960 \mathrm{mg} \mathrm{T/S}$ thrice weekly or of $300 \mathrm{mg}$ inhaled pentamidine in all AAV patients treated with GCs and Cyc [57].

Even though PCP is rare in large vessel vasculitis, the use of T/S prophylaxis in all PSV patients receiving GCs $>15 \mathrm{mg}$ per day and a GC-sparing immunosuppressant (for example, MTX) might be considered. As severe adverse event rates with T/S are generally low and cessation of the medication is reported in only about $3 \%$ of non-HIV-infected patients [58], generous use seems to be appropriate considering the still severe prognosis of PCP in this patient population [59]. However, the potential interaction of MTX and T/S has to be taken into account and strict folate substitution is mandatory. Furthermore, it has to be stressed that there is only little evidence from trials to support T/S prophylaxis in patients receiving medium potency immunosuppression. Its use should be discussed individually according to local praxis. 
It is not clear for how long PCP prophylaxis should be given. In some centres one criterion to stop PCP prophylaxis is a GC dose tapered below $15 \mathrm{mg}$ per day and/or the cessation of Cyc therapy. This praxis is based on the observation that $\mathrm{PCP}$ in non-HIV patients under GC medication occurred mainly with doses above $15 \mathrm{mg}$ per day [54]. In analogy to experiences in HIV patients, it has been suggested to measure CD4 cell counts and to stop prophylaxis when this value is above 200 per cubic millimetre [60]. However, other risk factors such as impaired cell functions are underestimated by this approach.

\section{Cytomegalovirus}

CMV is a herpesvirus that leads to latent infection. Its prevalence ranges between 60 and 100\%, depending on the geographic area [61]. CMV reactivation leads to a high burden of morbidity and mortality in immunocompromised persons, an interrelation best studied in transplantation medicine [62]. The spectrum of manifestations ranges from non-symptomatic infection to life-threatening disease, for example, pneumonitis. The scale of this problem in rheumatology and especially in PSV patients is insufficiently defined but appears to be less severe in most cases. In vasculitis patients leucopenia is the most frequent manifestation. However, in clinical trials some cases of CMV illness have been described with a relatively high proportion of fatal outcomes $[20,22,25]$. Large scale underreporting must be assumed, since until recent years reliable detection methods have been missing and the awareness of this problem appears to be still low. Mori and colleagues [63] found a high incidence of CMV reactivation in CMV-seropositive patients with connective tissue disease undergoing immunosuppressive therapy. A recent study by Takizawa and colleagues [39] suggests that GC use, especially in the form of pulsed methylprednisolone as well as other immunosuppressants, primarily Cyc, are the major risks factors for CMV reactivation in rheumatic diseases. In PSV, and especially in WG, CMV reactivation is an important differential diagnosis if neutropenia occurs.

In solid organ transplant recipients prophylaxis with, for example, ganciclovir or valganciclovir reduces CMV disease [64]. If CMV disease occurs in severely compromised patients with rheumatic diseases, anti-viral therapy might be without benefit as reported by Takizawa and colleagues [39] in a cohort of 85 patients. As CMV itself leads to further immunosuppression, fatal co-infections are promoted [39]. Taken together, these are arguments in favour of anti-viral prophylaxis in CMV-seropositive PSV patients undergoing intense immunosuppression. However, as data from clinical trials are missing, no evidence-based recommendation as to which patients should be introduced to prophylaxis can be given. In praxi prophylaxis (valganaciclovir $900 \mathrm{mg}$ once daily) might be considered only in severely ill PSV patients who need high dose methylprednisolone pulses or Cyc, especially if they had experienced earlier CMV reactivations. An alternative to this, as well as for other latently infected patients who need intense immunosuppression, is the preemptive approach, which also has been proven to be effective in organ-transplant recipients [65]. This requires quantitative monitoring of CMV - for example, by measurement of early antigen (pp65)-positive cells. Takizawa and colleagues [39] suggested a threshold of 5.6 pp65 positive cells per $10^{5}$ polymorphonuclear cells. Measurement of early antigen is increasingly replaced by quantitative CMV$\mathrm{PCR}$, which is currently the method of first choice.

\section{Varicella zoster virus}

Varicella zoster virus (VZV) reactivation leads to herpes zoster $(\mathrm{HZ})$. Whereas age is the most important risk factor for the development of $\mathrm{HZ}$ [66], autoimmune diseases and especially immunosuppressive therapy with Cyc and GCs further increases the probability of reactivation [67]. Several PSV trials report relatively high numbers of VZV reactivation and $H Z$ [28]. However, underreporting of this usually nonlife-threatening condition is likely. $\mathrm{HZ}$ causes substantial morbidity, especially when post-herpetic neuralgia develops, which is the case in up to $20 \%$ of the elderly population [68].

Despite these facts, no trial in PSV has included VZV prophylaxis to our knowledge, although it is feasible and effective at least in patients receiving haematopoietic stem cell transplantation using, for example, aciclovir $(2 \times 800 \mathrm{mg}$ per day) or valaciclovir [69]. The reason for not administering VZV prophylaxis in PSV may be the high potential for drug interactions and adverse events, especially in patients with renal impairment and the non-life- or organ-threatening nature of $\mathrm{HZ}$ in this population. In general, VZV prophylaxis is not recommended in PSV patients. It might be considered only in selected patients who have experienced several VZV reactivations and have an ongoing need for intense immunosuppression. More importantly, patients should be trained to recognise the early signs and symptoms of $\mathrm{HZ}$ to enable the immediate start of anti-viral therapy in the case of possible $\mathrm{HZ}$.

Vaccination to avoid $\mathrm{HZ}$ is available and effective [70]. In the US it is recommended by the Advisory Committee on Immunization Practices for all persons older than 60 years [70] but it is not recommended in patients under immunosuppressive medication [71]. Whether patients in remission from PSV under mild immunosuppression may benefit from vaccination warrants further investigation.

\section{Fungi}

Invasive fungal infections (other than PCP) are rare in PSV. Risk factors for the development of pulmonary Aspergillus sp. infections are prolonged episodes of neutropenia and prolonged use of high-dose GCs [72]. Few cases of invasive Aspergillus infections and fatalities in PSV have been reported [13,22,24]. 
Table 2

Possible use of anti-infective chemoprophylaxis in primary systemic vasculitis patients

\begin{tabular}{lll}
\hline Infectious agent & Prophylactic measure & Appropriate clinical situation \\
\hline Pneumocystis jiroveci & $\begin{array}{l}\text { Trimethoprim/sulfamethoxazole } 960 \mathrm{mg} \text { thrice } \\
\text { weekly. Alternative: monthly aerolized } \\
\text { pentamidine }(300 \mathrm{mg})\end{array}$ & $\begin{array}{l}\text { Should be given to all patients receiving } \\
\text { long term glucocorticoid }>15 \mathrm{mg} / \mathrm{day} \text { and } \\
\text { additional intense immunosuppression }\end{array}$
\end{tabular}

S. aureus Nasal mupirocin ointment three times daily for 7 consecutive days per month

Mycobacterium tuberculosis

Isoniazid $5 \mathrm{mg} / \mathrm{kg}$ per day up to $300 \mathrm{mg}$ plus pyridoxin (vitamin B6). Alternative: rifampin $10 \mathrm{mg} / \mathrm{kg}$ per day up to $600 \mathrm{mg}$

Varicella-zoster virus

Aciclovir $2 \times 800 \mathrm{mg}$ per day

Zoster vaccine

Cytomegalovirus

Valganaciclovir $1 \times 900 \mathrm{mg}$ per day

For example, posaconazole

Oral amphotericin B suspension,

$4 \times 1 \mathrm{ml}(=100 \mathrm{mg})$ per day
Might be given to patients with generalised

C

SVV who are $S$. aureus carriers during

induction of remission

If latent tuberculosis is detected and

C immunosuppression necessary, especially when infliximab is used

Generally not recommended, but might be

C considered in very selected cases with several reactivations and ongoing need for intense immunosuppression

Not recommended

C

Not generally recommended, but might be considered in selected severe cases with earlier reactivations and ongoing need for intense immunosuppression

Not recommended

C

Should be considered in patients with

C long term glucocorticoid therapy $>15 \mathrm{mg} /$ day

Level of evidence: $\mathrm{A}=$ evidence from at least one properly performed randomized controlled trial or meta-analysis of several controlled trials; $\mathrm{B}=$ well-conducted clinical studies, but no randomized clinical trials - evidence may be extensive but essentially descriptive; $\mathrm{C}=$ evidence obtained from expert committee reports or opinions, and/or clinical experience of respected authorities.

There is generally no indication for the prophylactic use of systemic anti-mycotics in PSV but aspergillosis should be considered as a differential diagnosis in patients if fever of unknown origin does not resolve under a calculated antibiotic therapy.

In contrast to invasive aspergillosis, Candida infections of mucosal membranes are a frequent complication of GC treatment, although leading to invasive candidiasis only very rarely. Nonetheless, oral candidiasis or candida esophagitis are painful and might hinder oral nutrition. In critically ill patients and solid organ transplant recipients prophylaxis using fluconazole is effective in avoiding invasive candidiasis $[73,74]$. Using topical non-absorbable antifungal prophylaxis in immunocompetent critically ill patients leads also to a significant reduction in fungal (mainly non-invasive) infections [75]. According to the BSR, prophylaxis with nystatin, ampho- tericin or fluconazole should be considered in all AAV patients receiving high-dose immunosuppressive therapy [57].

In praxi amphotericin suspension in all patients under long term GC medication with a dose of $>15 \mathrm{mg}$ prednisolone per day can be recommended because it is effective, nonabsorbable and associated, therefore, with very few side effects. According to a meta-analysis, the non-absorbable nystatin is not more effective in avoiding fungal colonisation than placebo and can not be recommended [76]. Additionally, all patients should be instructed to perform daily self-inspections of the mouth in order to detect mucosal candidiasis early.

\section{Mycobacterium tuberculosis}

Only a few cases of TB have been reported in PSV trials, although some of these have been fatal [16]. PSV studies 
using TNF- $\alpha$ blocking agents included TB screening as a reaction to $T B$ reactivations in early rheumatoid arthritis trials. Therefore, TB reactivation has not been seen in those studies $[9,10,19]$. While a general prophylaxis is clearly not indicated, screening for latent TB should be part of the work-up in PSV patients. For this purpose a full history, physical examination and a chest X-ray is recommended by the BSR guidelines [57], procedures that can be considered to be part of routine care. If latent TB is detected in a patient planned to start induction therapy for PVS, we recommend TB prophylaxis. According to a recent study, rifampin over 4 months might be safer and associated with better adherence than standard 9-month isoniazid [77]. As long as further trials are unavailable, we consider isoniazid plus vitamin B supplementation to be the standard of care, with rifampin being a good alternative in case of incompatibility.

In some PSV, especially in WG, infliximab is used as salvage therapy. In such cases screening and prophylaxis for TB should be performed as recommended for the use of infliximab in rheumatoid arthritis [78].

\section{Conclusion}

Infections significantly contribute to morbidity and mortality in PSV patients. There are three ways of targeting this problem: recognising and minimising risk factors, implementing prophylaxis where appropriate and ensuring early diagnosis and targeted therapy if infections occur. Although there is an ongoing need for better definitions of risk factors, from the available data it is quite clear that prolonged high-dose GC use is of central significance. Therefore, the reduction of GC dose must be a major aim in daily praxis as well as in future studies. To date, the only prophylactic measure that is recommended by national [57] and international guidelines [56] is T/S to avoid PCP in SVV patients undergoing intense immunosuppression. Further prophylaxis might be useful in specific clinical situations, as summarised in Table 2.

\section{Competing interests}

The authors declare that they have no competing interests.

\section{Acknowledgements}

This work was supported by "Deutsche Forschungsgemeinschaft" KFO 170.

\section{References}

1. Jayne DR, Gaskin G, Rasmussen N, Abramowicz D, Ferrario F, Guillevin L, Mirapeix E, Savage CO, Sinico RA, Stegeman CA, Westman KW, van der Woude FJ, de Lind van Wijngaarden RA, Pusey CD; European Vasculitis Study Group: Randomized trial of plasma exchange or high-dosage methylprednisolone as adjunctive therapy for severe renal vasculitis. J Am Soc Nephrol 2007, 18:2180-2188.

2. Bucaneve G, Micozzi A, Menichetti F, Martino P, Dionisi MS, Martinelli G, Allione B, D'Antonio D, Buelli M, Nosari AM, Cilloni D, Zuffa E, Cantaffa R, Specchia G, Amadori S, Fabbiano F, Deliliers GL, Lauria F, Foà R, Del Favero A; Gruppo Italiano Malattie Ematologiche dell'Adulto (GIMEMA) Infection Program: Levofloxacin to prevent bacterial infection in patients with cancer and neutropenia. N Engl J Med 2005, 353:977-987.
3. Cullen M, Steven N, Billingham L, Gaunt C, Hastings M, Simmonds P, Stuart N, Rea D, Bower M, Fernando I, Huddart R, Gollins S, Stanley A; Simple Investigation in Neutropenic Individuals of the Frequency of Infection after Chemotherapy +/- Antibiotic in a Number of Tumours (SIGNIFICANT) Trial Group: Simple Investigation in Neutropenic Individuals of the Frequency of Infection after Chemotherapy +/- Antibiotic in a Number of Tumours (SIGNIFICANT) Trial Group. Antibacterial prophylaxis after chemotherapy for solid tumors and lymphomas. $N$ Engl J Med 2005, 353:988-998.

4. Matteson EL, Gold KN, Bloch DA and Hunder GG: Long-term survival of patients with giant cell arteritis in the American College of Rheumatology giant cell arteritis classification criteria cohort. Am J Med 1996, 100:193-196.

5. Chevalet P, Barrier JH, Pottier P, Magadur-Joly G, Pottier MA, Hamidou M, Planchon B, El Kouri D, Connan L, Dupond JL, De Wazieres B, Dien G, Duhamel E, Grosbois B, Jego P, Le Strat A, Capdeville J, Letellier P, Agron L: A randomized, multicenter, controlled trial using intravenous pulses of methylprednisolone in the initial treatment of simple forms of giant cell arteritis: a one year followup study of 164 patients. J Rheumatol 2000, 27:1484-1491.

6. Jover JA, Hernández-García C, Morado IC, Vargas E, Bañares A, Fernández-Gutiérrez B: Combined treatment of giant-cell arteritis with methotrexate and prednisone. a randomized, double-blind, placebo-controlled trial. Ann Intern Med 2001, 134:106-114.

7. Hoffman GS, Cid MC, Hellmann DB, Guillevin L, Stone JH, Schousboe J, Cohen P, Calabrese LH, Dickler H, Merkel PA, Fortin P, Flynn JA, Locker GA, Easley KA, Schned E, Hunder GG, Sneller MC, Tuggle C, Swanson H, Hernández-Rodríguez J, Lopez-Soto A, Bork D, Hoffman DB, Kalunian K, Klashman D, Wilke WS, Scheetz RJ, Mandell BF, Fessler BJ, Kosmorsky G, et al:: A multicenter, randomized, double-blind, placebo-controlled trial of adjuvant methotrexate treatment for giant cell arteritis. Arthritis Rheum 2002, 46:1309-1318.

8. Mazlumzadeh M, Hunder GG, Easley KA, Calamia KT, Matteson EL, Griffing WL, Younge BR, Weyand CM, Goronzy JJ: Treatment of giant cell arteritis using induction therapy with highdose glucocorticoids: a double-blind, placebo-controlled, randomized prospective clinical trial. Arthritis Rheum 2006, 54: 3310-3318.

9. Hoffman GS, Cid MC, Rendt-Zagar KE, Merkel PA, Weyand CM, Stone JH, Salvarani C, Xu W, Visvanathan S, Rahman MU; Infliximab-GCA Study Group: Infliximab for maintenance of glucocorticosteroid-induced remission of giant cell arteritis: a randomized trial. Ann Intern Med 2007, 146:621-630.

10. Martínez-Taboada VM, Rodríguez-Valverde V, Carreño L, LópezLongo J, Figueroa M, Belzunegui J, Mola EM, Bonilla G: A double-blind placebo controlled trial of etanercept in patients with giant cell arteritis and corticosteroid side effects. Ann Rheum Dis 2008, 67:625-630.

11. Hoffman GS, Merkel PA, Brasington RD, Lenschow DJ, Liang P: Anti-tumor necrosis factor therapy in patients with difficult to treat Takayasu arteritis. Arthritis Rheum 2004, 50:2296-2304.

12. Cohen $P$, Pagnoux $C$, Mahr A, Arène JP, Mouthon L, Le Guern V, André MH, Gayraud M, Jayne D, Blöckmans D, Cordier JF, Guillevin L; French Vasculitis Study Group: Churg-Strauss syndrome with poor-prognosis factors: A prospective multicenter trial comparing glucocorticoids and six or twelve cyclophosphamide pulses in forty-eight patients. Arthritis Rheum 2007, 57:686-693.

13. Gayraud M, Guillevin L, Cohen P, Lhote F, Cacoub P, Deblois P, Godeau B, Ruel M, Vidal E, Piontud M, Ducroix JP, Lassoued S, Christoforov B, Babinet P: Treatment of good-prognosis polyarteritis nodosa and Churg-Strauss syndrome: comparison of steroids and oral or pulse cyclophosphamide in 25 patients. French Cooperative Study Group for Vasculitides. $\mathrm{Br}$ $J$ Rheumatol 1997, 36:1290-1297.

14. Guillevin L, Lhote F, Cohen P, Jarrousse B, Lortholary O, Généreau T, Léon A, Bussel A: Corticosteroids plus pulse cyclophosphamide and plasma exchanges versus corticosteroids plus pulse cyclophosphamide alone in the treatment of polyarteritis nodosa and Churg-Strauss syndrome patients with factors predicting poor prognosis. A prospective, randomized trial in sixty-two patients. Arthritis Rheum 1995, 38:1638-1645. 
15. Guillevin L, Fain O, Lhote F, Jarrousse B, Le Thi Huong D, Bussel $A$, Leon $A$ : Lack of superiority of steroids plus plasma exchange to steroids alone in the treatment of polyarteritis nodosa and Churg-Strauss syndrome. A prospective, randomized trial in 78 patients. Arthritis Rheum 1992, 35:208215.

16. Guillevin L, Jarrousse B, Lok C, Lhote F, Jais JP, Le Thi Huong Du $D$, Bussel $A$ : Longterm followup after treatment of polyarteritis nodosa and Churg-Strauss angiitis with comparison of steroids, plasma exchange and cyclophosphamide to steroids and plasma exchange. A prospective randomized trial of 71 patients. The Cooperative Study Group for Polyarteritis Nodosa. J Rheumatol 1991, 18:567-574.

17. Nachman $\mathrm{PH}$, Hogan $\mathrm{SL}$, Jennette JC, Falk RJ: Treatment response and relapse in antineutrophil cytoplasmic autoantibody-associated microscopic polyangiitis and glomerulonephritis. J Am Soc Nephrol 1996, 7:33-39.

18. Metzler C, Miehle N, Manger K, Iking-Konert C, de Groot K, Hellmich B, Gross WL, Reinhold-Keller E; German Network of Rheumatic Diseases: Elevated relapse rate under oral methotrexate versus leflunomide for maintenance of remission in Wegener's granulomatosis. Rheumatology (Oxford) 2007, 46:1087-1091.

19. WGET Research Group: Etanercept plus standard therapy for Wegener's granulomatosis. N Engl J Med 2005, 352:351-361.

20. Schmitt WH, Hagen EC, Neumann I, Nowack R, Flores-Suárez LF, van der Woude FJ: Treatment of refractory Wegener's granulomatosis with antithymocyte globulin (ATG): an open study in 15 patients. Kidney Int 2004, 65:1440-1448.

21. Metzler C, Fink C, Lamprecht P, Gross WL, Reinhold-Keller E: Maintenance of remission with leflunomide in Wegener's granulomatosis. Rheumatology (Oxford) 2004, 43:315-320.

22. Bligny D, Mahr A, Toumelin PL, Mouthon L, Guillevin L: Predicting mortality in systemic Wegener's granulomatosis: a survival analysis based on 93 patients. Arthritis Rheum 2004, 51: 83-91.

23. Reinhold-Keller E, Fink CO, Herlyn K, Gross WL, De Groot K: High rate of renal relapse in 71 patients with Wegener's granulomatosis under maintenance of remission with low-dose methotrexate. Arthritis Rheum 2002, 47:326-332.

24. Mahr A, Girard T, Agher R, Guillevin L: Analysis of factors predictive of survival based on 49 patients with systemic Wegener's granulomatosis and prospective follow-up. Rheumatology (Oxford) 2001, 40:492-498.

25. Reinhold-Keller E, Beuge N, Latza U, de Groot K, Rudert H, Nölle B, Heller M, Gross WL: An interdisciplinary approach to the care of patients with Wegener's granulomatosis: long-term outcome in 155 patients. Arthritis Rheum 2000, 43:1021-1032.

26. Guillevin L, Cordier JF, Lhote F, Cohen P, Jarrousse B, Royer I, Lesavre $P$, Jacquot $C$, Bindi $P$, Bielefeld $P$, Desson JF, Détrée $F$, Dubois A, Hachulla E, Hoen B, Jacomy D, Seigneuric C, Lauque $\mathrm{D}$, Stern M, Longy-Boursier M: A prospective, multicenter, randomized trial comparing steroids and pulse cyclophosphamide versus steroids and oral cyclophosphamide in the treatment of generalized Wegener's granulomatosis. Arthritis Rheum 1997, 40:2187-2198.

27. de Groot K, Reinhold-Keller E, Tatsis E, Paulsen J, Heller M, Nölle $B$, Gross WL: Therapy for the maintenance of remission in sixty-five patients with generalized Wegener's granulomatosis. Methotrexate versus trimethoprim/sulfamethoxazole. Arthritis Rheum 1996, 39:2052-2061.

28. Stegeman CA, Tervaert JW, de Jong PE, Kallenberg CG: Trimethoprim-sulfamethoxazole (co-trimoxazole) for the prevention of relapses of Wegener's granulomatosis. $N$ Engl J Med 1996, 335:16-20.

29. Sneller MC, Hoffman GS, Talar-Williams C, Kerr GS, Hallahan CW, Fauci AS: An analysis of forty-two Wegener's granulomatosis patients treated with methotrexate and prednisone. Arthritis Rheum 1995, 38:608-613.

30. Pagnoux C, Mahr A, Hamidou MA, Boffa JJ, Ruivard M, Ducroix JP, Kyndt X, Lifermann F, Papo T, Lambert M, Le Noach J, Khellaf $M$, Merrien D, Puéchal X, Vinzio S, Cohen $P$, Mouthon L, Cordier JF, Guillevin L; French Vasculitis Study Group: Azathioprine or methotrexate mainenance for ANCA-associated vasculitis. $N$ Engl J Med 2008, 359:2790-2803.

31. Walsh M, Chaudhry A, Jayne D: Long-term follow-up of relapsing/refractory anti-neutrophil cytoplasm antibody associated vasculitis treated with the lymphocyte depleting antibody alemtuzumab (CAMPATH-1H). Ann Rheum Dis 2008, 67: 1322-1327.

32. De Groot K, Rasmussen N, Bacon PA, Tervaert JW, Feighery C Gregorini G, Gross WL, Luqmani R, Jayne DR: Randomized trial of cyclophosphamide versus methotrexate for induction of remission in early systemic antineutrophil cytoplasmic antibody-associated vasculitis. Arthritis Rheum 2005, 52:24612469.

33. Booth A, Harper L, Hammad T, Bacon P, Griffith M, Levy J, Savage C, Pusey C, Jayne D: Prospective study of TNFalpha blockade with infliximab in anti-neutrophil cytoplasmic antibody-associated systemic vasculitis. J Am Soc Nephrol 2004, 15:717-721.

34. Birck R, Warnatz K, Lorenz HM, Choi M, Haubitz M, Grünke M, Peter HH, Kalden JR, Göbel U, Drexler JM, Hotta O, Nowack R, Van Der Woude FJ: 15-Deoxyspergualin in patients with refractory ANCA-associated systemic vasculitis: a six-month open-label trial to evaluate safety and efficacy. $J A m$ Soc Nephrol 2003, 14:440-447.

35. Jayne D, Rasmussen N, Andrassy K, Bacon P, Tervaert JW, Dadoniené J, Ekstrand A, Gaskin G, Gregorini G, de Groot K, Gross W, Hagen EC, Mirapeix E, Pettersson E, Siegert C, Sinico A, Tesar V, Westman K, Pusey C; European Vasculitis Study Group: European Vasculitis Study Group. A randomized trial of maintenance therapy for vasculitis associated with antineutrophil cytoplasmic autoantibodies. N Engl J Med 2003, 349:36-44.

36. Haubitz M, Schellong S, Göbel U, Schurek HJ, Schaumann D, Koch KM, Brunkhorst R: Intravenous pulse administration of cyclophosphamide versus daily oral treatment in patients with antineutrophil cytoplasmic antibody-associated vasculitis and renal involvement: a prospective, randomized study. Arthritis Rheum 1998, 41:1835-18344.

37. de Groot K, Harper L, Jayne DR, Flores Suarez LF, Gregorini G, Gross WL, Luqmani R, Pusey CD, Rasmussen N, Sinico RA, Tesar V, Vanhille P, Westman K, Savage CO; EUVAS (European Vasculitis Study Group): Pulse versus daily oral cyclophosphamide for induction of remission in Antineutrophil cytoplasmic antibody-associated vasculitis. Ann Int Med 2009, 150:670-680.

38. Charlier C, Henegar C, Launay O, Pagnoux C, Berezné A, Bienvenu $B$, Cohen P, Mouthon L, Guillevin L: Risk factors for major infections in Wegener's granulomatosis: analysis of 113 patients. Ann Rheum Dis 2008, 68:658-663.

39. Takizawa Y, Inokuma S, Tanaka Y, Saito K, Atsumi T, Hirakata M, Kameda H, Hirohata S, Kondo H, Kumagai S, Tanaka Y: Clinical characteristics of cytomegalovirus infection in rheumatic diseases: multicentre survey in a large patient population. Rheumatology (Oxford) 2008, 47:1373-1378.

40. Proven A, Gabriel SE, Orces C, O'Fallon WM, Hunder GG: Glucocorticoid therapy in giant cell arteritis: duration and adverse outcomes. Arthritis Care Res 2003, 49:703-708.

41. Schmidt J, Duhaut P, Smail V, Chatelain D, Bosshard S, Pellet H, Piette J, Ducroix J: Severe infections during giant cell arteritis course: incidence and mortalitiy. The prospective, multicentre double cohort GRACG study. Ann Rheum Dis 2009, 68s:80

42. Hellmich B, Flossmann O, Gross WL, Bacon P, Cohen-Tervaert JW, Guillevin L, Jayne D, Mahr A, Merkel PA, Raspe H, Scott DG, Witter J, Yazici H, Luqmani RA: EULAR recommendations for conducting clinical studies and / or clinical trials in systemic vasculitis: focus on anti-neutrophil cytoplasm antibody-associated vasculitis. Ann Rheum Dis 2007, 66:605-617.

43. Moosig F, Lamprecht $P$, Gross WL: Wegener's granulomatosis: the current view. Clin Rev Allergy Immunol 2008, 35:19-21.

44. Ullrich S, Gustke H, Lamprecht P, Gross WL, Schumacher U Ambrosch $\mathrm{P}$, Laudien M: Severely impaired respiratory ciliar function in Wegener's granulomatosis. Ann Rheum Dis 2008, 68:1067-1071.

45. Bosch X, Guilabert A, Espinosa G, Mirapeix E: Treatment of antineutrophil cytoplasmic antibody-associated vasculitis. JAMA 2007, 298:655-669.

46. Van Rijen M, Bonten M, Wenzel R, Kluytmans J: Mupirocin ointment for preventing Staphylococcus aureus infections in nasal carriers. Cochrane Database Syst Rev 2008, 4:CD006216.

47. Stegeman CA, Tervaert JW, Sluiter WJ, Manson WL, de Jong PE, Kallenberg CG: Association of chronic nasal carriage of $\mathrm{S}$. 
aureus and higher relapse rates in Wegener's granulomatosis. Ann Intern Med 1994, 120:12-17.

48. Pinching AJ, Rees AJ, Pussell BA, Lockwood CM, Mitchison RS, Peters DK: Relapses in Wegener's granulomatosis: the role of infection. BMJ 1980, 281:836-838.

49. Fauci AS, Haynes BF, Katz P, Wolff SM: Wegener's granulomatosis: prospective clinical and therapeutical experience with 85 patients for 21 years. Ann Intern Med 1983, 98:76-85.

50. DeRemee RA, McDonald TJ, Weiland LH. Wegener's granulomatosis: observations on treatment with antimicrobial agents. Mayo Clin Proc 1985, 60:27-32.

51. Ognibene FP, Shelhamer JH, Hoffman GS, Kerr GS, Reda D, Fauci AS, Leavitt RY: Penumocystis carinii pneumonia: a major complication of immunosuppressive therapy in patients with Wegener's granulomatosis. Am J Respir Crit Care Med 1995, 151:795-799.

52. Godeau B, Mainardi JL, Roudot-Thoraval F, Hachulla E, Guillevin L, Huong Du LT, Jarrousse B, Remy P, Schaeffer A, Piette JC: Factors associated with Pneumocystis carinii pneumonia in Wegener's granulomatosis. Ann Rheum Dis 1995, 54:991-994.

53. Yale SH, Limper AH: Pneumocystis carinii pneumonia in patients without acquired immunodeficiency syndrome: associated illness and prior corticosteroid therapy. Mayo Clin Proc 1996, 71:5-13.

54. Sowden E, Carmichael AJ: Autoimmune inflammatory disorders, systemic corticosteroids and pneumocystis pneumonia: a strategy for prevention. BMC Infect Dis 2004, 4:42-48.

55. Chung JB, Armstrong K, Schwartz JS, Albert D: Cost-effectiveness of prophylaxis against Pneumocystis carinii pneumonia in patients with Wegener's granulomatosis undergoing immunosuppressive therapy. Arthritis Rheum 2000, 43:18411848.

56. Mukhtyar C, Guillevin L, Cid MC, Dasgupta B, de Groot K, Gross W, Hauser T, Hellmich B, Jayne D, Kallenberg CG, Merkel PA, Raspe H, Salvarani C, Scott DG, Stegeman C, Watts R, Westman K, Witter J, Yazici H, Luqmani R; European Vasculitis Study Group: EULAR recommendations for the management of primary small and medium vessel vasculitis. Ann Rheum Dis 2008, 68:310-317.

57. Lapraik C, Watts R, Bacon P, Carruthers D, Chakravarty K, D'Cruz D, Guillevin L, Harper L, Jayne D, Luqmani R, Mooney J, Scott D; BSR and BHPR Standards, Guidelines and Audit Working Group: BSR and BHPR guidelines for the management of adults with ANCA associated vasculitis. Rheumato/ogy (Oxford) 2007, 46:1615-1616.

58. Green H, Paul M, Vidal L, Leibovici L: Prophylaxis of Pneumocystis pneumonia in immunocompromised non-hiv-infected patients: Systematic review and meta-analysis of randomized controlled trials. Mayo Clin Proc 2007, 82:1052-1059.

59. Mansharamani NG, Garland R, Delaney D, Koziel H: Management and outcome patterns for adult Pneumocystis carinii pneumonia, 1985 to 1995: comparison of HIV-associated cases to other immunocompromised states. Chest 2000, 118: 704-711.

60. Suryaprasad A, Stone $\mathrm{JH}$ : When is it safe to stop Pneumocystis jiroveci pneumonia prophylaxis? Insights from three cases complicating autoimmune diseases. Arthritis Rheum 2008, 59: 1034-1039.

61. Krech U: Complement-fixing antibodies against cytomegalovirus in different parts of the world. Bull World Health Organ 1973, 49:103-106.

62. Brennan DC: Cytomegalovirus in renal transplantation. $J A m$ Soc Nephrol 2001, 12:848-855.

63. Mori $T$, Kameda $H$, Ogawa $H$, lizuka A Sekiguchi $N$, Takei $H$ Nagasawa H, Tokuhira M, Tanaka T, Saito Y, Amano K, Abe T, Takeuchi $\mathrm{T}$ : Incidence of cytomegalovirus reactivation in patients with inflammatory connective tissue diseases who are under immunosuppressive therapy. J Rheumatol 2004, 31: 1349-1351.

64. Paya C, Humar A, Dominguez E, Washburn K, Blumberg E, Alexander B, Freeman R, Heaton N, Pescovitz MD; Valganciclovir Solid Organ Transplant Study Group: Efficacy and safety of valganciclovir vs. oral ganciclovir for prevention of cytomegalovirus disease in solid organ transplant recipients. Am J Transplant 2004, 4:611-620.

65. Kalil AC, Levitsky J, Lyden E, Stoner J, Freifeld AG: Meta-analysis: the efficacy of strategies to prevent organ disease by cytomegalovirus in solid organ transplant recipients. Ann Intern Med 2005, 143:870-880.

66. Ragozzino MW, Melton LJ 3d, Kurland LT, Chu CP, Perry HO: Population-based study of herpes zoster and its sequelae. Medicine (Baltimore) 1982, 61:310-316

67. Smitten AL, Choi HK, Hochberg MC, Suissa S, Simon TA, Testa MA, Chan KA: The risk of herpes zoster in patients with rheumatoid arthritis in the United States and the United Kingdom. Arthritis Rheum 2007, 57:1431-1438.

68. Oxman MN, Levin MJ, Johnson GR, Schmader KE, Straus SE, Gelb LD, Arbeit RD, Simberkoff MS, Gershon AA, Davis LE, Weinberg A, Boardman KD, Williams HM, Zhang JH, Peduzzi PN Beisel CE, Morrison VA, Guatelli JC, Brooks PA, Kauffman CA, Pachucki CT, Neuzil KM, Betts RF, Wright PF, Griffin MR, Brunell $P$, Soto NE, Marques AR, Keay SK, Goodman RP,: A vaccine to prevent herpes zoster and postherpetic neuralgia in older adults. N Engl J Med 2005, 352:2271-2284.

69. Boeckh M, Kim HW, Flowers ME, Meyers JD, Bowden RA: Longterm acyclovir for prevention of varicella zoster virus disease after allogeneic hematopoietic cell transplantation - a randomized double-blind placebo-controlled study. Blood 2006, 107:1800-1805.

70. Harpaz R, Ortega-Sanchez IR, Seward JF: Prevention of herpes zoster: recommendations of the Advisory Committee on Immunization Practices (ACIP). MMWR Recomm Rep 2008, 57:1-30.

71. Kimberlin DW, Whitley RJ: Varicella-zoster vaccine for the prevention of herpes zoster. N Engl J Med 2007, 356:1338-1343.

72. Segal $\mathrm{BH}$, Walsh TJ: Current approaches to diagnosis and treatment of invasive aspergillosis. Am J Respir Crit Care Med 2006, 173:707-717.

73. Playford EG, Webster AC, Sorrell TC, Craig JC: Antifungal agents for preventing fungal infections in non-neutropenic critically ill and surgical patients: systematic review and metaanalysis of randomized clinical trials. J Antimicrob Chemother 2006, 57:628-638.

74. Playford EG, Webster AC, Sorrell TC, Craig JC: Antifungal agents for preventing fungal infections in non-neutropenic critically ill patients. Cochrane Database Syst Rev 2006:CD004920

75. Ho KM, Rochford SA, John G: The use of topical nonabsorbable gastrointestinal antifungal prophylaxis to prevent fungal infections in critically ill immunocompetent patients: a meta-analysis. Crit Care Med 2005, 33:2383-2392.

76. Gøtzsche PC, Johansen HK: Nystatin prophylaxis and treatment in severely immunodepressed patients. Cochrane Database Syst Rev 2002:CD002033.

77. Menzies D, Long R, Trajman A, Dion MJ, Yang J, Al Jahdali $H$, Memish Z, Khan K, Gardam M, Hoeppner V, Benedetti A, Schwartzman K: Adverse events with 4 months of rifampin therapy or 9 months of isoniazid therapy for latent tuberculosis infection: a randomized trial. Ann Intern Med 2008, 149: 689-697.

78. Saag KG, Teng GG, Patkar NM, Anuntiyo J, Finney C, Curtis JR, Paulus HE, Mudano A, Pisu M, Elkins-Melton M, Outman R, Allison JJ, Suarez Almazor M, Bridges SL Jr, Chatham WW, Hochberg M, MacLean C, Mikuls T, Moreland LW, O'Dell J, Turkiewicz AM, Furst DE; American College of Rheumatology: American College of Rheumatology. American College of Rheumatology 2008 recommendations for the use of nonbiologic and biologic disease-modifying antirheumatic drugs in rheumatoid arthritis. Arthritis Rheum 2008, 59:762-784. 